\title{
Characterization of the Neuroprotective Effect of the Cannabinoid Agonist WIN-55212 in an In Vitro Model of Hypoxic-Ischemic Brain Damage in Newborn Rats
}

\author{
DAVID FERNÁNDEZ-LÓPEZ, JOSÉ MARTÍNEZ-ORGADO, ESTEFANÍA NUÑEZ, JULIÁN ROMERO, PEDRO LORENZO, \\ MARIA ÁNGELES MORO, AND IGNACIO LIZASOAIN
}

Departamento de Farmacología [D.F.-L., P.L., MAM., IL], Facultad de Medicina, Universidad Complutense, 28040 Madrid, Spain; Área de Pediatría y Neonatología [J.M.-O.], Laboratorio de Apoyo a la Investigación [E.N., J.R.], Fundación Hospital Alcorcón, 28922

Alcorcón (Madrid), Spain

\begin{abstract}
Brain slices from 7-d-old Wistar rats were exposed to oxygen-glucose deprivation (OGD) for $30 \mathrm{~min}$. OGD slices were incubated with vehicle or with the CB1/CB2 cannabinoid agonist WIN55212 $(50 \mu \mathrm{M})$, the CB1 agonist arachidonyl-2-chloroethylamide (ACEA) $(50 \mu \mathrm{M})$, or the CB2 agonist JW133 $(50 \mu \mathrm{M})$, alone or combined with the CB1 and CB2 receptor antagonist SR 141716 (50 $\mu \mathrm{M})$ or SR $144528(50 \mu \mathrm{M})$, respectively. Neuronal damage was assessed by histologic analysis and spectrophotometric determination of lactate dehydrogenase (LDH) efflux into the incubation medium. Additionally, medium glutamate levels were determined by highperformance liquid chromatography (HPLC) and those of tumor necrosis factor $\alpha$ (TNF- $\alpha$ ) by enzyme-linked immunosorbent assay. Finally, inducible nitric oxide synthase (iNOS) and CB1/CB2 receptor expression were determined in slices homogenate by Western blot. Both $\mathrm{CB} 1$ and $\mathrm{CB} 2$ receptors were expressed in slices. OGD increased CB1 expression, cellular damage, LDH efflux, glutamate and TNF- $\alpha$ release, and inducible nitric oxide synthase (iNOS) expression; WIN55212 inhibited all these actions. SR141716 and SR144528 inhibited the effect of R(+)-WIN-55212-2 (WIN), as well as the reduction of LDH efflux by ACEA and JW133, respectively. In conclusion, WIN55212 afforded robust neuroprotection in the forebrain slices exposed to OGD, by acting on glutamatergic excitotoxicity, TNF- $\alpha$ release, and iNOS expression; this neuroprotective effect seemed to be mediated by $\mathrm{CB} 1$ and $\mathrm{CB} 2$ receptors. (Pediatr Res 60: 169-173, 2006)
\end{abstract}

$\mathrm{P}^{\mathrm{s}}$ erinatal hypoxia-ischemia remains the single most important cause of brain injury in the newborn, leading to death or lifelong sequelae $(1,2)$. The complexities of neonatal hypoxic-ischemic encephalopathy (NHIE) pathophysiology suggest that successful neuroprotection could be achieved only with a multitherapeutic approach (2). In recent years, interest in the neuroprotective possibilities of cannabinoids has grown (3-5). Endocannabinoids emerge as natural brain protective substances in different damaging situations $(3,4)$; in newborn

Received December 1, 2005; accepted March 29, 2006

Correspondence: José Martínez-Orgado, M.D., Ph.D., Area de Pediatría y Neonatología, Fundación Hospital Alcorcón, Avda. Budapest 1, 28922 Alcorcón (Madrid), Spain; e-mail: jamartinezo@fhalcorcon.es

This work was supported by grants from Sociedad Española de Neonatología 2000 (J.M.-O.), FIS-PI021540 (J.M.-O.), FIS-PI030304 (M.A.M.), SAF 2004-00237 (J.R.), and SAF2005-05960 (I.L.).

DOI: 10.1203/01.pdr.0000228839.00122.6c rats, enhanced levels of cannabinoids have been observed in the brain after acute excitotoxic insult (6). Exogenous cannabinoid agonists are neuroprotective in different paradigms of brain injury $(7,8)$; they inhibit intracellular calcium influx, reduce glutamate and $\mathrm{TNF}-\alpha$ release, decrease stimulated iNOS expression, induce hypothermia, and exert immunomodulatory and antioxidant actions $(3-5,9,10)$. Some of these effects are dependent on the activation of the principal brain cannabinoid receptors, the $\mathrm{CB} 1$ receptors, and others are dependent on the molecular properties of the cannabinoid or the activation of non-CB1 receptors (3). There are few studies regarding the possible neuroprotective effect of cannabinoids in newborns. Early studies describe that the administration of anandamide (11) or the cannabinoid agonist $\Delta$ (9)tetrahydrocannabinol (12) affords neuroprotection in a newborn rat model with excitotoxic neuronal injury. It has also been demonstrated that the cannabinoid agonist WIN, prevents early neuronal death by CB1-independent mechanisms, and prevents late neuronal death by CB1-dependent mechanisms in a model of acute asphyxia in newborn rats (13).

In our study, we investigated the mechanisms involved in the prevention of early hypoxic-ischemic neuronal death in the newborn rat brain using WIN. This involved an in vitro model using the exposure of newborn rat brain slices to OGD. This reproduces most the mechanisms of hypoxic-ischemic damage in the newborn brain, as glutamatergic excitotoxicity, cytokine release, or NO toxicity, with characteristics different from those of adult rat brain slice OGD; it is therefore considered an in vitro model of NHIE (14).

\section{METHODS}

Preparation and incubation of slices. The experimental protocol has been described elsewhere (14). Briefly, newborn Wistar rats (7-10 d old) were killed by decapitation (according to the Committee of Animal Care at the Universidad Complutense of Madrid), the forebrain was removed and coronally cut ( $1 \mathrm{~mm}$ anterior and $3 \mathrm{~mm}$ posterior to the bregma), and the central portion was sliced $(0.5 \mathrm{~mm}$ slice thickness) using a Vibroslice (WPI, Stevenage, UK) into cold $\left(12-14^{\circ} \mathrm{C}\right)$ modified Krebs-Henseleit solution (preincubation solution) containing $(\mathrm{mM}): \mathrm{NaCl}(120), \mathrm{KCl}(2), \mathrm{CaCl} 2(0.5)$,

Abbreviations: iNOS, inducible nitric oxide synthase; LDH, lactate dehydrogenase; NHIE, neonatal hypoxic-ischemic encephalopathy; OGD, oxygen-glucose deprivation; WIN, R(+)-WIN-55212-2 
NaHCO3 (26), MgSO4 (10), KH2PO4 (1.18), glucose (11), and sucrose (200). Slices were incubated in sucrose-free preincubation solution for $45 \mathrm{~min}$ and later in a modified Krebs-Henseleit solution (incubation solution) containing (mM): $\mathrm{NaCl}(120), \mathrm{KCl}(2), \mathrm{CaCl} 2$ (2), $\mathrm{NaHCO} 3$ (26), $\mathrm{MgSO} 4$ (1.19), $\mathrm{KH} 2 \mathrm{PO} 4$ (1.18), glucose (11) and 5,6,7,8-tetrahydrobiopterin (BH4, $10 \mathrm{mM}$ ), bubbled with $95 \% \mathrm{O}_{2} / 5 \% \mathrm{CO}_{2}$ in a shaking water bath at $37^{\circ} \mathrm{C}$.

The slices of the control group (CG, $n=28$ ) were then incubated $30 \mathrm{~min}$ further in the same conditions, and slices of the "ischemic" experimental group (OGD, $n=30$ ) were incubated for $30 \mathrm{~min}$ in incubation solution without glucose and equilibrated with $95 \% \mathrm{~N}_{2} / 5 \% \mathrm{CO}_{2}$. In all groups, the end of the period of $30 \mathrm{~min}$ was considered as time $0(\mathrm{t} 0)$. After these periods of $30 \mathrm{~min}$, the medium was replaced with fresh incubation solution equilibrated with $95 \% \mathrm{O}_{2} / 5 \% \mathrm{CO}_{2}$ ("reperfusion" phase). Thereafter, the incubation solution was renewed every $30 \mathrm{~min}$, up to and including $150 \mathrm{~min}$ (t150). Samples were taken each time the incubation solution was replaced, except the sample to determine TNF- $\alpha$ levels, which was collected once only at t150. At $\mathrm{t} 150$, slices were taken out and frozen immediately with liquid nitrogen.

Before starting to study the neuroprotective effect of WIN, tests were run using a concentration of WIN from 0.5 to $100 \mu \mathrm{M}$, to obtain the optimal drug concentration. Next, at this optimal concentration, WIN alone (WIN, $n=14$ ), or with the CB1 receptor antagonist SR141716 (50 $\mu \mathrm{M}$; SR1, $n=7)$, or the CB2 receptor antagonist SR144528 $(50 \mu \mathrm{M}, n=8)$ was added to the preincubation solution, remaining present until the end of the experiment. In another set of experiments, the CB1-specific agonist arachidonyl-2chloroethylamide (ACEA) $(50 \mu \mathrm{M}, n=10)$, alone or with SR1 $(50 \mu \mathrm{M}, n=$ 8 ), or the CB2-specific agonist 1,1-dimethylbutyl-1-deoxy- $\Delta$ (9)tetrahydrocannabinol (JWH133) (50 $\mu \mathrm{M}$; JW, $n=10)$, alone or with SR2 (50 $\mu \mathrm{M}, n=8$ ) was added.

Histologic study. At the end of the experiment, the brain slices were fixed overnight in $4 \%$ paraformaldehyde. They were then embedded in paraffin and cut into $3-\mu \mathrm{m}$ sections using a microtome. Each section was stained using Nissl's technique and observed with a Nikon Eclipse 90i microscope with a Nikon Digital Camera DXM 1200F, coupled to computerized imageprocessing software (Metamorph 6.3r1, Molecular Devices Corp.). Digital microphotographs $(\times 400)$ were taken from three different $500-\mu \mathrm{m}^{2}$ areas of striatum using slices from at least three different specimens to count viable neurons with their nuclei present in the focal plane. Cell counting was performed by an investigator blinded to the experimental protocol.

LDH activity assay. As a marker of necrotic tissue damage, LDH released from damaged cells in the slices was determined in the incubation solution, as previously described (14). LDH activity was measured spectrophotometrically at $340 \mathrm{~nm}$ by following the oxidation of NADH (decrease in absorbance) in the presence of pyruvate using a Thermomax microplate reader (Molecular Devices, Sunnyvale, CA). LDH efflux was expressed as the LDH activity present in the incubation solution. Data are expressed as $\mathrm{mOD} / \mathrm{min}$ and reflect the total LDH release.

HPLC determination of glutamate concentration. Samples of the incubation solution were collected at t0. Analysis of glutamate in each sample was performed by HPLC with fluorimetric detection (Perkin Elmer Binary LC Pump 250 and Fluorescence Detector LC 240) following precolumn derivatization with the o-phtalaldialdehyde procedure, as previously described (14). Glutamate derivatives were separated isocratically on a reverse phase column $(4.6 \times 150 \mathrm{~mm}, 5-\mathrm{mm}$ particle diameter, Nucleosil 100-C18) using a mobile phase consisting of sodium acetate buffer $(0.05 \mathrm{M}, \mathrm{pH} 6.5), 20 \%$ methanol and $2 \%$ tetrahydrofuran. The area of each peak was determined with a Perkin Elmer Nelson Model 1020 integrator (Phoenix 8088 ROM BIOS Version 2.52 software) and compared with the peak area of the corresponding external standard. The limit of detection in these conditions was $10 \mathrm{ng} / \mathrm{mL}$.

Western blot analyses. For analysis of iNOS, CB1, and CB2 expression, slices were homogenized in lysis buffer (10 mM Tris, $\mathrm{pH} 8.0 ; 0.2 \%$ Nonidet P-40;1 mM dithioerythritol); after centrifugation for $15 \mathrm{~min}$, the proteins present in the supernatant were loaded $(10 \mu \mathrm{g})$ and size-separated in $10 \%$ SDS-polyacrylamide gel electrophoresis $(50 \mathrm{~mA})$, as previously described (14). The gels were blotted onto a PVDF membrane (Millipore, Bedford, MA), incubated with specific polyclonal antibodies against iNOS (Santa Cruz Biotechnology, Santa Cruz, CA; 1:1000 dilution), CB1 and CB2 (Chemicon International Inc; both at a 1:300 dilution), and processed as recommended by the supplier. Proteins recognized by the antibodies were revealed by an ECL kit following the manufacturer's instructions (Amersham Iberica, Madrid, Spain). INOS, CB1, and CB2 expression was quantified by densitometric analysis of bands. Commercial markers (Bio-Rad prestained) were used as molecular weight standards, and $\beta$-actin was used to normalize the protein lane charge of the blot.

TNF- $\alpha$ determination. Soluble TNF- $\alpha$ released from cells into the incubation solution was determined by a rat TNF- $\alpha$ immunoassay (Rat TNF- $\alpha$ UltraSensitive, Biosource International Inc., Camarillo, CA.
Chemicals and statistical analyses. SR141716 and SR144528 were a generous gift from Sanofi-Synthelabo (Paris, France). BH4 was obtained from RBI, and, unless otherwise stated, the other chemicals were from Sigma Chemical Co. (Madrid, Spain).

Results are expressed as mean \pm SEM of the indicated number of experiments. Statistical comparisons were made using analysis of variance (ANOVA), with the Newman-Keuls test for multiple comparisons. A $p$ value $<0.05$ was considered as statistically significant. Statistical analysis was performed using the 11.0.0 version of SPSS software (SPSS Inc.).

\section{RESULTS}

Expression of the cannabinoid receptors $\mathrm{CB} 1$ and $\mathrm{CB} 2$. Western blot analysis at t150 demonstrated the presence of the $\mathrm{CB} 1$ and $\mathrm{CB} 2$ receptors in the CG. OGD induced a significant increase in $\mathrm{CB} 1$ expression but not an increase in CB2 expression (Fig. 1).

Characterization of the effect of WIN on brain injury after $\boldsymbol{O G D}$. As observed after Nissl staining, OGD led to severe tissue damage, with a large reduction in the number of viable neurons (Fig. 2). Viable striatal neuron density was $348.4 \pm$ 14.6 versus. $33.3 \pm 2.8$ per $\mathrm{mm}^{2}$ for $\mathrm{CG}$ and OGD, respectively. In CG, LDH efflux was minimal and remained stable throughout the 150-min experimental period; by contrast, OGD induced a significant increase in LDH efflux during the entire experimental period, as we have described previously (14) (Fig. 3). Prior incubation of OGD slices with WIN reduced LDH efflux in a dose-dependent manner (Fig. 3). A concentration of $50 \mu \mathrm{M}$ was the most effective dose, reducing LDH efflux to levels similar to those in CG (Fig. 3). Higher concentration, however, further increased LDH efflux, suggesting some toxic effect (Fig. 3). Thus, a concentration of 50 $\mu \mathrm{M}$ was selected as the optimal WIN concentration for experiments. Based on its $K i$ values, similar concentration of ACEA and JW were selected after testing showed a higher concentration was not more effective.

In addition to reducing LDH efflux, WIN increased the number of viable neurons observed under the microscope (264.1 \pm 10.9 per $\mathrm{mm}^{2}, p<0.05$ versus OGD) (Fig. 2). Co-incubation with either SR1 or SR2 inhibited both protective effects of WIN (Figs. 2 and $4 A$ ); neuronal density was $50.1 \pm 2.3$ and $59.5 \pm 3.1$ per $\mathrm{mm}^{2}$ for SR1 and SR2,
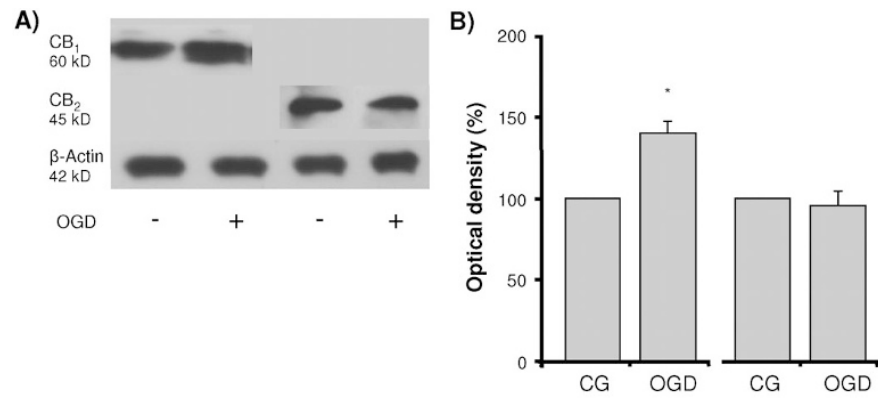

Figure 1. Determination of $\mathrm{CB} 1$ and $\mathrm{CB} 2$ expression in homogenates of the brain slices from 7-d-old rats, maintained in physiologic solution (CG), or after OGD. (A) Representative Western blot. (B) Quantification of CB1 (left columns) and CB2 (right columns) expression by densitometric analysis, expressed as a percentage of the optic density of the protein band in CG. Commercial markers (Bio-Rad prestained) were used as molecular weight standards. $\beta$-Actin was used to normalize the protein lane charge of the blot. Bars represent the mean \pm SEM of five to seven experiments. *ANOVA, $p$ $<0.05$ vs CG. 


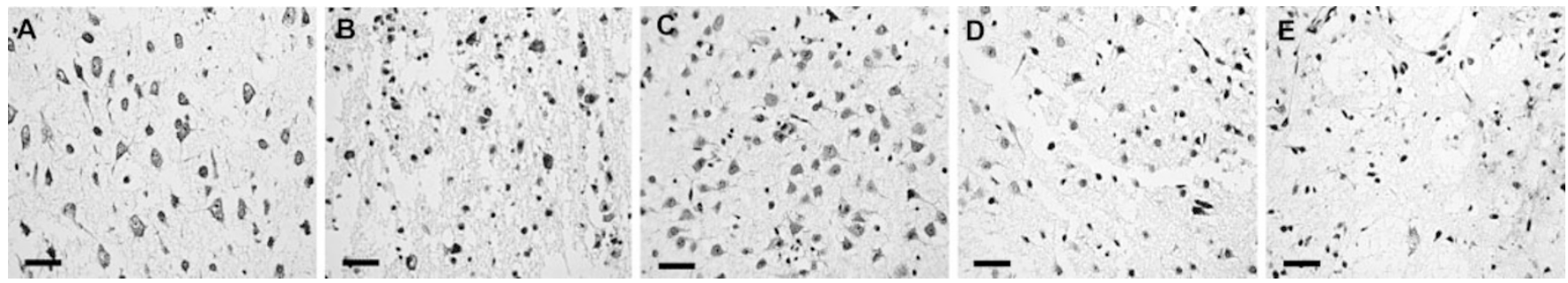

Figure 2. Light micrographs of striatum neurons from coronal brain slices from 7-d-old rats after Nissl staining (original magnification, $\times 400$ ), showing examples of a brain slice maintained in physiologic solution (CG) $(A)$; a brain slice after OGD $(B)$; a brain slice after OGD incubated with WIN55212 (50 $\mu$ M) $(C)$; a brain slice after OGD co-incubated with WIN + SR141716 $(50 \mu \mathrm{M})(D)$; and a brain slice after OGD co-incubated with WIN + SR144528 $(50 \mu \mathrm{M})(E)$. Scale bar: $100 \mu \mathrm{m}$.

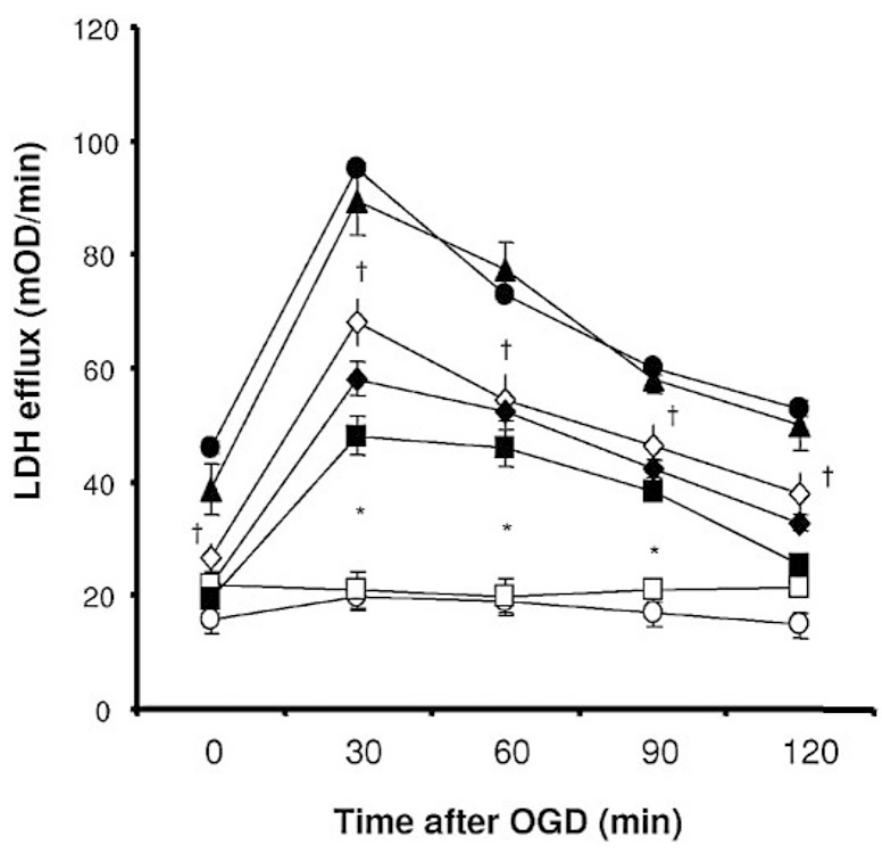

Figure 3. Time profile of LDH efflux in brain slices from 7-d-old rats maintained in physiologic solution (CG, open circles), or after OGD without treatment (filled circles) or with WIN55212 $(0.5 \mu \mathrm{M}$, filled triangles; $1 \mu \mathrm{M}$, open diamonds; $10 \mu \mathrm{M}$, filled diamonds; $50 \mu \mathrm{M}$, open squares; or $100 \mu \mathrm{M}$, filled squares). LDH efflux was quantified as LDH activity measured spectrophotometrically and expressed in $\mathrm{mOD} / \mathrm{min}$. Points represent the mean \pm SEM of six to 10 experiments. ${ }^{*} p<0.05 v s$ control; $\dagger p<0.05 v s$ OGD.

respectively ( $p<0.05$ versus CG and WIN). Co-incubation of WIN with SR1 and SR2 together had no additional inhibiting effect (data not shown).

Incubation with ACEA or JW reduced LDH efflux, but to a lesser extent than with WIN (Fig. 4B). The effect was receptor specific, as SR1 reversed the effect of ACEA as did SR2 with JW (data not shown).

Effect of WIN on glutamate and TNF- $\alpha$ concentration and iNOS expression. OGD induced a significant increase in glutamate concentration in the incubation medium (Fig. 5A). This increase was reduced by WIN to $<50 \%$ of the OGD values (Fig. 5A). Co-incubation with SR1 or SR2 eliminated the WIN-induced reduction of glutamate concentration.

When compared with $\mathrm{CG}$, exposure to OGD caused a twofold increase in TNF- $\alpha$ concentration (Fig. 5B). WIN inhibited this increase in TNF- $\alpha$, with concentrations lower than those found in CG. Co-incubation with SR1 or SR2 inhibited the TNF- $\alpha$ reduction by WIN.
A)
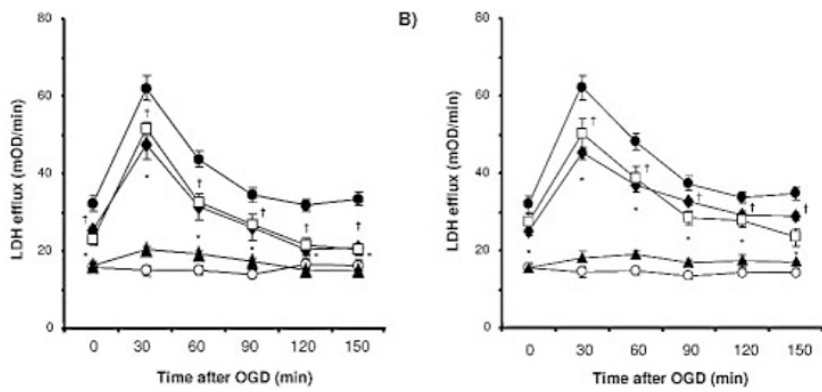

Figure 4. Time profile of LDH efflux in brain slices from 7-d-old rats, maintained in physiologic solution (CG, open circles) or after OGD without treatment (filled circles) or incubated with WIN55212 $(50 \mu \mathrm{M}$; filled triangles $), \mathrm{WIN}+\mathrm{SR} 141716(50 \mu \mathrm{M} ;$ filled diamonds $)$, or WIN + SR144528 (50 $\mu \mathrm{M}$; open squares) $(A)$ or with WIN55212 (50 $\mu \mathrm{M}$; filled triangles), ACEA (50 $\mu \mathrm{M}$; open squares), or JW133 (50 $\mu \mathrm{M}$; filled diamonds) (B). LDH efflux was quantified as LDH activity measured spectrophotometrically and expressed in $\mathrm{mOD} / \mathrm{min}$. Points represent the mean \pm SEM of 12 to 30 experiments. ${ }^{*} p<0.05 v s$ control; $\dagger p<0.05$ vs OGD.
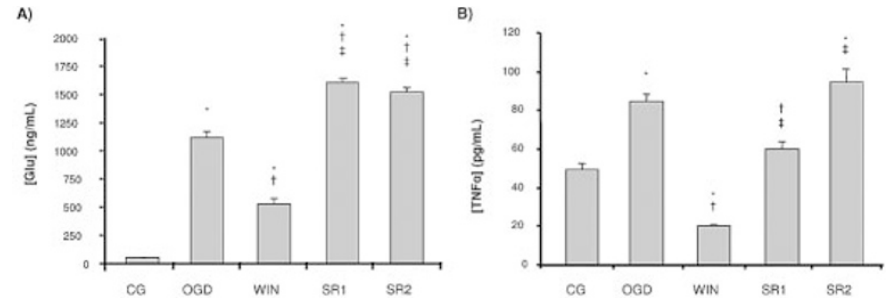

Figure 5. Measurements in the incubating medium of brain slices from 7-d-old rats maintained in physiologic solution $(\mathrm{CG}, n=30)$ or after OGD without treatment (OGD) or with WIN55212 (50 $\mu \mathrm{M}$; WIN), WIN + SR141716 $(50 \mu \mathrm{M} ; \mathrm{W}+\mathrm{SR} 1)$, or WIN + SR144528 (50 $\mu \mathrm{M} ; \mathrm{W}+\mathrm{SR} 2)$ of glutamate concentration, by HPLC at the end of OGD $(A)$. TNF- $\alpha$ concentration, by enzyme-linked immunosorbent assay at the end of the experiment (B). Bars represent the mean \pm SEM of seven to 30 experiments. *ANOVA, $p<0.05$ vs CG; †ANOVA, $p<0.05$ vs OGD; †ANOVA, $p<0.05 v s$ WIN.

In CG slice homogenate, a small expression of iNOS was detected by Western blot analysis (Fig. 6). In contrast, OGD caused a strong overexpression of iNOS (Fig. 4). This overexpression was attenuated by WIN (Fig. 6). This effect of WIN was counteracted by SR1 or SR2 co-incubation (Fig. 6).

\section{DISCUSSION}

We have demonstrated for the first time that (1) a cannabinoid agonist induced a robust neuroprotective effect in an in vitro model of NHIE; (2) this neuroprotective effect is related to the modulation of some relevant factors involved in hy- 
A)

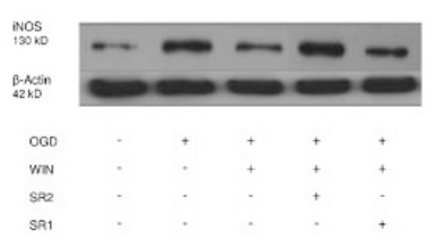

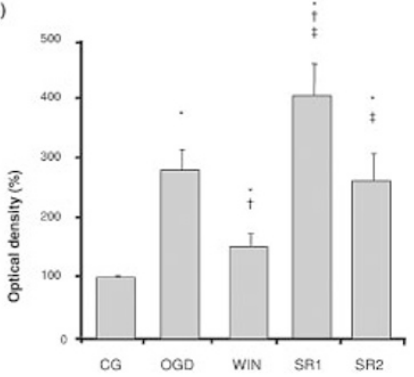

Figure 6. Determination of iNOS expression in homogenates of brain slices from 7-d-old rats, maintained in physiologic solution (CG), or after OGD without treatment (OGD) or with WIN55212 (50 $\mu \mathrm{M}$; WIN), WIN + SR141716 (50 $\mu \mathrm{M}$; W+SR1), or WIN + SR144528 (50 $\mu \mathrm{M}$; W+SR2). (A) Representative Western-Blot. (B) Quantification of iNOS expression by densitometric analysis, expressed as percentage of the optic density of the iNOS protein band in CG. Bars represent the mean \pm SEM of five to seven experiments. *ANOVA, $p<0.05$ vs $\mathrm{CG}$

poxic-ischemic brain damage; (3) CB2 receptors play a relevant role, offering interesting therapeutic options; and (4) the simultaneous activation of both $\mathrm{CB} 1$ and $\mathrm{CB} 2$ receptors offers more benefits than $\mathrm{CB} 1$ or $\mathrm{CB} 2$ activation alone.

The neuroprotective effects shown confirm those previously observed by us in an in vivo model of NHIE in rats (13) and offer cannabinoids as a promising strategy against acute neurodegeneration $(3,4,7,8)$. The $50-\mu \mathrm{M}$ dose of WIN used is higher than that commonly used in cell cultures (7) due to the thickness of the forebrain slices $(500 \mu \mathrm{m})$. These required greater drug concentrations to achieve appropriate WIN concentration in the deepest layers of the slice. LDH efflux in brain slices incubated with $50 \mu \mathrm{M}$ of WIN remained stable throughout the experiment and at levels similar to those of the CG, supporting the neuroprotective effect of WIN and also its lack of toxic effects. Our experiments have analyzed for the first time the effects of a cannabinoid on the activation of some critical factors that determine neuronal death in NHIE. These factors include glutamatergic excitotoxicity, TNF- $\alpha$ release, and iNOS expression $(1,2)$. The immature brain is selectively vulnerable to glutamatergic excitotoxicity $(1,14-16)$. WIN reduced glutamate concentration in the incubation medium when compared with untreated OGD brain slices alone. Drugs reducing glutamate release are of particular value in neuroprotection in NHIE, as glutamate receptor blockers are neurotoxic in immature brains (2). Cannabinoids are known to inhibit glutamate release by presynaptic $G$ protein-coupled receptor activation (17-22).

WIN led to a decrease in TNF- $\alpha$ release. Great attention is paid to the role of TNF- $\alpha$ in NHIE because it is particularly harmful to the immature brain. It is involved in apoptotic and oxidative injury processes using different mechanisms, including iNOS induction $(1,14,23,24)$. Cannabinoids inhibit the increase in TNF- $\alpha$ production after immunologic stimuli, both in vivo and in vitro (10) by modulating different transcriptional factors (25) and enhancing the release of the endogenous interleukin-1 receptor antagonist (IL-1ra) (26). In addition to this, cannabinoids reduce the release of glutamate, which in turn enhances TNF- $\alpha$ release by activation of its secretase, TNF- $\alpha$ convertase (TACE/ADAM17) (27). Interestingly,

WIN reduced TNF- $\alpha$ concentrations to an even lower level than those of the $\mathrm{CG}$, suggesting that some stimulation of TNF- $\alpha$ release derived from brain slice manipulation occurs, thus emphasizing the anti-inflammatory effect of cannabinoids $(5,10,26)$.

Expression of iNOS was increased by OGD, as reported $(14,28)$. Different mechanisms participate in iNOS induction during hypoxia, including $\mathrm{TNF}-\alpha$ (23) or glutamate (28) release; massive production of $\mathrm{NO}$ after induction of iNOS plays a major role in hypoxic brain injury $(1,16,29)$. The induction of iNOS after OGD was counteracted by WIN. Cannabinoids inhibit iNOS expression in glial cells after different stimuli $(9,26,30)$ by enhancing IL-1ra release $(26)$ and inhibiting the transcriptional activity of the nuclear factor $-\kappa \mathrm{B}(\mathrm{NF}-\kappa \mathrm{B})(9,31)$. This effect on NF- $\kappa \mathrm{B}$ activity is of particular importance because this is the mechanism by which glutamate induces the expression of iNOS (28).

Western blot revealed the presence of $\mathrm{CB} 1$ receptors in newborn rat brain slices and, for the first time, CB2 receptors. The neuroprotective effect of WIN was eliminated by SR1 and SR2, suggesting the participation of both $\mathrm{CB} 1$ and $\mathrm{CB} 2$ receptors in this effect. $\mathrm{CB} 1$ receptors are found in the brain during the early prenatal developmental stages, increasing in density soon after birth (32). CB1 was overexpressed $150 \mathrm{~min}$ after OGD, as observed $2 \mathrm{~h}$ after focal ischemia in the rat brain (33). This agrees with the suggested role of endocannabinoids as natural neuroprotectors after brain injuries $(4,6)$. Our results suggesting the participation of CB1 receptors in WIN-induced neuroprotection are supported by $\mathrm{LDH}$ efflux reduction by ACEA and confirm previous results from ischemic brain injury experiments in mice (34). SR1 reversed the WINinduced reduction of glutamate release. Although the role of CB1 in cannabinoid reduction of glutamate release in adult brain remains controversial (17-22), our results support a role for these receptors in cannabinoid prevention of excitotoxic damage in newborn brain, as reported $(11,12)$. SR1 not only reversed the WIN-induced reduction of glutamate release, but increased OGD-induced glutamate release. Similar results were observed in cultured cerebellar neurons and have been interpreted as inverse agonism of SR1 or the block in activity of endogenous ligands at cannabinoid receptors (17). We also confirmed the involvement of $\mathrm{CB} 1$ receptors in WIN modulation of TNF- $\alpha$ release and iNOS expression enhancement, an effect thought to be exerted on glial cells $(9,10)$.

Recently, CB2 receptors have been discovered in brain neurons (35) and microglial cells (36), both being present in the forebrain slices that we used. A striking result of our study was the elimination of WIN neuroprotection by SR2. JW, a selective CB2 agonist, was also equally capable of reducing LDH efflux. This is, to our knowledge, the first report of CB2 intermediation of cannabinoid neuroprotection in models of brain ischemia. $\mathrm{CB} 2$ receptors are overexpressed in glial cells in different paradigms of inflammatory brain insult $(37,38)$; although inflammation plays a pivotal role in ischemic brain damage (24), we did not observe an increase in CB2 expression in OGD brain slices. It has been reported that in cultured cells, CB2 receptors participate in the reduction by cannabinoids, of lipolysaccharide-induced TNF- $\alpha$ release (10) and 
iNOS expression increase $(26,30)$; ours is the first evidence of a CB2-mediated reduction of TNF- $\alpha$ release and iNOS expression in a model of hypoxic-ischemic brain damage. In addition, we have also described for the first time that CB2 participated in the reduction of glutamate release by WIN, involving them in the modulatory effect of cannabinoids on excitotoxic brain damage. Our results support the possibility of a cannabinoid-based therapeutic intervention, free from psychotropic effects, as CB2 receptors do not mediate the psychoactive effects of cannabinoids (39).

Interestingly, the neuroprotective effect of WIN, a CB1/ CB2 agonist, was greater than that of selective $\mathrm{CB} 1$ or CB2 agonists. In fact, LDH efflux was similar in $\mathrm{WIN}+\mathrm{SR} 1$ and $\mathrm{JW}$, as well as in WIN+SR2 and ACEA. These data suggest that simultaneous activation of both $\mathrm{CB} 1$ and $\mathrm{CB} 2$ receptors was more effective in modulating the factors involved in hypoxic-ischemic brain damage than $\mathrm{CB} 1$ or $\mathrm{CB} 2$ alone. Studies on neuronal and glial cultures have shown that the neuroprotective action of cannabinoids in response to inflammatory or excitotoxic insults is mediated by both CB1 and CB2 receptor-dependent pathways (26). Co-incubation of WIN with SR1 and SR2 did not increase the inhibitory effect of SR1 or SR2 alone, suggesting that WIN might also act on receptor(s) other than CB1 and CB2 (21).

In conclusion, WIN showed a robust neuroprotective effect on 7-d-old rat forebrain slices exposed to OGD, based on the reduction of glutamate release, TNF- $\alpha$ release, and iNOS expression. The effect of WIN was mediated by both CB1 and CB2 receptors. Our results support a major role for cannabinoids in neuroprotective strategies, opening an exciting field of investigation in the role of CB2 receptors in NHIE pathophysiology and therapeutics.

Acknowledgments. We are grateful to Andrew Lumsden for his help in reviewing the manuscript and to Ruth Pazos, Cristina Benito, and Rosa M. Tolón from the Laboratorio de Apoyo a la Investigación of the Fundación Hospital Alcorcón for their excellent technical assistance.

\section{REFERENCES}

1. du Plessis AJ, Volpe JJ 2002 Perinatal brain injury in the preterm and term newborn. Curr Opin Neurol 15:151-157

2. Hamrick SE, Ferriero DM 2003 The injury response in the term newborn brain: can we neuroprotect? Curr Opin Neurol 16:147-154

3. Grundy RI, Rabuffetti M, Beltramo M 2001 Cannabinoids and neuroprotection. Mol Neurobiol 24:29-51

4. Mechoulam R, Panikashvili D, Shohami E 2002 Cannabinoids and brain injury: therapeutic implications. Trends Mol Med 8:58-61

5. Howlett AC, Breivogel CS, Childers SR, Deadwyler SA, Hampson RE, Porrino LJ 2004 Cannabinoid physiology and pharmacology: 30 years of progress. Neuropharmacology 47:345-358

6. Hansen HH, Schmid PC, Bittigau P, Lastres-Becker I, Barrendero F, Manzanares J, Ikonomidou C, Schmid HH, Fernández-Ruiz JJ, Hansen HH 2001 Anandamide, but not 2-arachidonylglycerol, accumulates during in vivo neurodegeneration. J Neurochem 78:1415-1427

7. Nagayama T, Sinor AD, Simon RP, Chen J, Graham SH, Jin K, Greenberg DA 1999 Cannabinoids and neuroprotection in global and focal cerebral ischemia and in neuronal cultures. J Neurosci 19:2987-2995

8. Sinor AD, Irvin SM, Greenberg DA 2000 Endocannabinoids protect cerebral cortical neurons from in vitro ischemia in rats. Neurosci Lett 278:157-160

9. Waksman Y, Olson JM, Carlisle SJ, Cabral GA 1999 The central cannabinoid receptor (CB1) mediates inhibition of nitric oxide production by rat microglial cells. J Pharmacol Exp Ther 288:1357-1366

10. Klein TW, Lane B, Newton CA, Friedman H 2000 The cannabinoid system and cytokine network. Proc Soc Exp Biol Med 225:1-8
11. Van der Stelt M, Veldhuis WB, Van Haaften GW, Fezza F, Bisogno T, Bär PR, Veldink GA, Vliegenthart JF, Di Marzo V, Nicolay K 2001 Exogenous anandamide protects rat brain against acute neuronal injury in vivo. J Neurosci 21:8765-8771

12. Van der Stelt M, Veldhuis WB, Bär PR, Veldink GA, Vliegenthart JF, Nicolay K 2001 Neuroprotection by $\Delta 9$-tetrahydrocannabinol, the main active compound in marijuana, against ouabain-induced in vivo excitotoxicity. J Neurosci 21:6475-6479

13. Martínez-Orgado J, Fernández-Frutos B, González R, Romero E, Urigüen L, Romero J, Viveros MP 2003 Neuroprotection by the cannabinoid agonist WIN-55212 in an in vivo newborn rat model of acute severe asphyxia. Mol Brain Res 114:132-139

14. Fernandez-Lopez D, Martinez-Orgado J, Casanova I, Bonet B, Leza JC, Lorenzo P, Moro MA, Lizasoain I 2005 Immature rat brain slices exposed to oxygen-glucose deprivation as an in vitro model of neonatal hypoxic-ischemic encephalopathy. J Neurosci Methods 145:205-212

15. Johnston MV 2001 Excitotoxicity in neonatal hypoxia. Ment Retard Dev Disabil Res Rev 7:229-234

16. Mishra OP, Fritz KI, Delivoria-Papadopoulos M 2001 NMDA receptor and neonatal hypoxic brain injury. Ment Retard Dev Disabil Res Rev 7:249-253

17. Breivogel CS, Walker JM, Huang SM, Roy MB, Childers SR 2004 Cannabinoid signaling in rat cerebellar granule cells: G-protein activation, inhibition of glutamate release and endogenous cannabinoids. Neuropharmacology 47:81-91

18. Melis M, Pistis M, Perra S, Muntoni AL, Pillolla G, Gessa GL 2004 Endocannabinoids mediate presynaptic inhibition of glutamatergic transmission in rat ventral tegmental area dopamine neurons through activation of CB1 receptors. J Neurosci 24:53-62

19. Köfalvi A, Vizi ES, Ledent C, Sperlágh B 2003 Cannabinoids inhibit the release of $[3 \mathrm{H}]$ glutamate from rodent hippocampal synaptosomes via a novel CB1 receptor action. Eur J Neurosci 18:1973-1978

20. Hajos N, Ledent C, Freund TF 2001 Novel cannabinoid-sensitive receptor mediates inhibition of glutamatergic synaptic transmission in the hippocampus. Neuroscience 106:1-4

21. Hájos N, Freund TF 2002 Pharmacological separation of cannabinoid sensitive receptors on hippocampal excitatory and inhibitory fibers. Neuropharmacology 43:503-510

22. Brown TM, Brotchie JM, Fitzjohn SM 2003 Cannabinoids decrease corticostriatal synaptic transmission via an effect on glutamate uptake. J Neurosci 23:11073-11077

23. Hurtado O, Cárdenas A, Lizasoain I, Boscá L, Leza JC, Lorenzo P, Moro MA 2001 Up-regulation of TNF- $\alpha$ convertase (TACE/ADAM17) after oxygen and glucose deprivation in rat forebrain slices. Neuropharmacology 40:1094-1102

24. Allan SM, Rothwell NJ 2001 Cytokines and acute neurodegeneration. Nat Rev Neurosci 2:734-744

25. Croxford JL, Miller SD 2003 Immunoregulation of a viral model of multiple sclerosis using the synthetic cannabinoid R(+)WIN55,212. J Clin Invest 111:1231-1240

26. Molina-Holgado F, Pinteaux E, Moore JD, Molina-Holgado E, Guaza C, Gibson RM, Rothwell N 2003 Endogenous interleukin-1 receptor antagonist mediates anti-inflammatory and neuroprotective actions of cannabinoids in neurons and glia. J Neurosci 23:6470-6474

27. Hurtado O, Lizasoain I, Fernandez-Tome P, Alvarez-Barrientos A, Leza JC, Lorenzo $P$ Moro MA 2002 TACE/ADAM17-TNF-alpha pathway in rat cortical cultures after exposure to oxygen-glucose deprivation or glutamate. J Cereb Blood Flow Metab 22:576-585

28. Cárdenas A, Moro MA, Hurtado O, Leza JC, Lorenzo P, Castrillo A, Bodegón OG, Boscá L, Lizasoain I 2000 Implication of glutamate in the expression of inducible nitric oxide synthase after oxygen and glucose deprivation in rat forebrain slices. J Neurochem 74:2041-2048

29. Lizasoain I, Moro MA, Knowles RG, Darley-Usmar V, Moncada S 1996 Nitric oxide and peroxynitrite exert distinct effects on respiration by brain mitochondria which are differentially blocked by glutathione or glucose. Biochem J 314:877-880

30. Molina-Holgado F, Molina-Holgado E, Guaza C, Rothwell NJ 2002 Role of CB1 and CB2 receptors in the inhibitory effects of cannabinoids on lipopolysaccharideinduced nitric oxide release in astrocyte cultures. J Neurosci Res 67:829-836

31. Jüttler E, Potrovita I, Tarabin V, Prinz S, Dong-Si , Fink G, Schwaninger M 2004 The cannabinoid dexanabinol is an inhibitor of the nuclear factor kappa B (NF- $\kappa \mathrm{B})$. Neuropharmacology 47:580-592

32. Fride E 2004 The endocannabinoid-CB1 receptor system in pre- and postnatal life. Eur J Pharmacol 500:289-297

33. Jin KL, Mao XO, Goldsmith PC, Greenberg DA 2000 CB1 cannabinoid receptor induction in experimental stroke. Ann Neurol 48:257-261

34. Parmentier-Batteur S, Jin K, Mao XO, Xie L, Greenberg DA 2002 Increased severity of stroke in CB1 cannabinoid receptor knock-out mice. J Neurosci 22:9771-9775

35. Van Sickle MD, Duncan M, Kingsley PJ, Mouihate A, Urbani P, Mackie K, Stella N, Makriyannis A, Piomelli D, Davison JS, Marnett LJ, Di Marzo V, Pittman QJ, Patel KD, Sharkey KA 2005 Identification and functional characterization of brainstem cannabinoid CB2 receptors. Science 310:329-332

36. Maresz K, Carrier EJ, Ponomarev ED, Hillard CJ, Dittel BN 2005 Modulation of the cannabinoid CB2 receptor in microglial cells in response to inflammatory stimuli. J Neurochem 95:437-445

37. Benito C, Núñez E, Tolón RM, Carrier EJ, Rábano A, Hillard CJ, Romero J 2003 Cannabinoid CB2 receptors and fatty acid amide hydrolase are selectively overexpressed in neuritic plaque-associated glia in Alzheimer's disease brains. J Neurosci 23:11136-11141

38. Carlisle SJ, Marciano-Cabral F, Staab A, Ludwick C, Cabral GA 2002 Differential expression of the CB2 cannabinoid receptor by rodent macrophages and macrophage-like cells in relation to cell activation. Int Immunopharmacol 2:69-82

39. Howlett AC, Barth F, Bonner TI, Cabral G, Casellas G, Devane WA, Felder CC, Herkenham M, Mackie K, Martin BR, Mechoulam R, Pertwee RG 2002 International Union of Pharmacology. XXVII. Classification of cannabinoid receptors. Pharmacol Rev 54:161-202 